\title{
The planetary piggy bank
}

Nature's Services: Societal Dependence on Natural Ecosystems edited by Gretchen C. Daily

Island: 1997. Pp 392. \$49.95 (hbk); \$24.95, $\mathfrak{E} 19.95$ (pbk)

\section{The Work of Nature: How the} Diversity of Life Sustains Us by Yvonne Baskin

Island: 1997. Pp 263. \$25, £19.95

\section{Mary Power}

Within the past few months, these two new books and an article in Nature have addressed the value of ecosystem services. What does nature do for the human enterprise, and how much are its services worth, in cash? Posing this question may initially seem crass or misguided, recalling the greed and foolishness of King Midas, whose myth reverberates today in the anecdote closing a chapter by Rosalind Naylor and Paul Ehrlich in Nature's Services.

After a speaker at a US Federal Trade Commission meeting dismissed the threat of global warming by pointing out that agriculture and forestry account for only 3 per cent of US gross national product, the audience overheard a distinguished economist comment: "What does this genius think we're going to eat?"

Practical, ethical and aesthetic problems of putting a price on nature, as well as the ultimately incalculable value of natural lifesupport on our planet, are acknowledged upfront in these two books, as well as by Robert Costanza and colleagues in their Nature article $(387,253 ; 1997$ (see also News and Views, 387, 231; 1997)).

Nevertheless, all these authors make compelling cases for why the valuation exercise is crucial. Ecosystem services, defined in Nature's Services as "the goods and life support functions provided by natural ecosystems and their species that sustain and fulfill human life", have long been undervalued and understudied. By attempting to price services such as water purification, pest control or climate amelioration, these authors provide some of the first quantitative estimates - at ecosystem, regional and global scales - of "what is lost when we degrade the free services that nature provides". Tailored to specific regions or watersheds, such information would greatly improve our ability to take explicit account of the tradeoffs we make in the course of decisions about land use.

The two books and the Nature article are lucid, substantive and authoritative. Taken together, there is surprisingly little redundancy, with different and complementary emphases.

Costanza gathered economic and ecological colleagues to develop a total valuation for the world's ecosystem services and natural capital. Their estimate, $\$ 33$ million million a year, is the sum of the estimated annual global value of 17 types of services distributed among 21 biomes. This is almost certainly an underestimate, given the lack of information on some biomes or types of services, several conservative economic assumptions and, snapshot estimate. As supplies diminish, values of commodities or services increase, exponentially to infinity if there is no substitute.

The Costanza estimate is clearly not robust, given its sensitivity to complex and dynamic ecological and economic forces. Yet it is extremely useful, if only to cause reflection that this conservative estimate is already twice the global annual gross national product.

In Nature's Services the emphasis shifts from a total valuation to estimating the marginal values of ecosystem services. Marginal values are defined in the book as "prices people are willing to pay for each successive increase in an ecosystem service, or the value consumers place on the last unit purchased".

This estimate can be broken into two parts: the increment (or decrement) in human welfare gained from a small change in an ecosystem service, and the change in the ecosystem service caused by a small change in policy. These values are chalmost importantly, the static nature of this

lenging to measure and clearly depend on where slopes are measured along curves relating the variables. Therefore, like total valuation estimates, marginal values also depend on context and assumptions.

Nevertheless, the task of measuring the marginal value of a particular ecosystem service in a particular region is extremely heuristic. The approach focuses the problem so that quantitative models with operationally defined terms and explicit testable assumptions can be applied to evaluate land use issues and eventually (dare we hope?) assist in predicting the ecological-economic system's behaviour under various scenarios. The challenge of determining the way in which small changes in policy affect ecosystem states and processes, and how these affect human society, sets an important research agenda.

Nature's Services is an important first step in this line of enquiry. It moves the study of ecosystem services beyond its earlier phase, during which a handful of workers presented global case studies of ecosystem services and pleaded for recognition of their importance.

Nature's Services begins with Gretchen C. Daily's overview of ecosystem services, in which she frames and defines key issues. Philosophical and historical comments follow by Daily, N. Myers, J. S. Reichert, J. P. Myers, H. A. Mooney and P. R. Ehrlich. Two

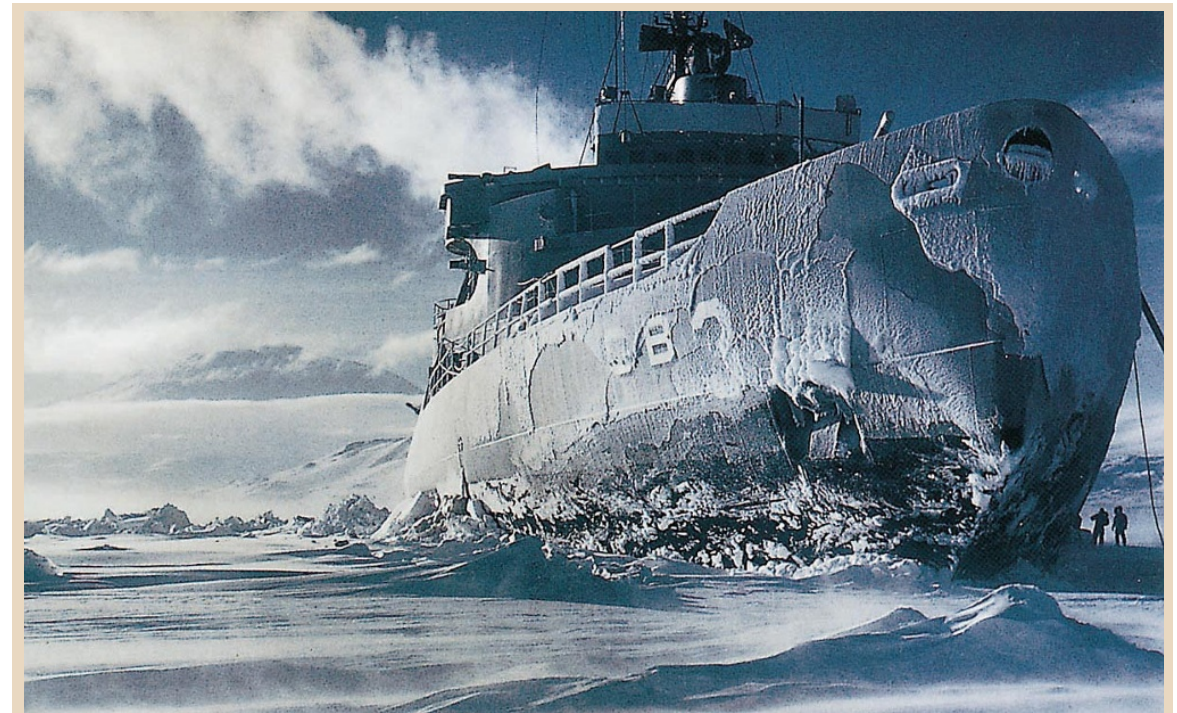

\section{Life in the freezer}

Glaciologist Charles Swithinbank worked for many years for the US Antarctic Program. His career spanned a period of unprecedented change: "Schooled, as I was, in the British tradition of traveling the hard way, with manhauled sledges, dog teams, and spartan rations, my move to the US plunged me into a world of giant icebreakers [above], aircraft, tractors, gourmet food, and a US Naval Task Force struggling to come to terms with the eccentric ways of scientists." Swithinbank describes his "adventures in the pursuit of science" in An Alien in Antarctica: Reflections upon Forty Years of Exploration and Research on the Frozen Continent (McDonald and Woodward, \$49.95). 
chapters on economics follow in which L. H. Goulder and D. Kennedy review alternative approaches to valuation and R. Costanza and C. Folke discuss how valuations are complicated by context, including the many different goals of societies.

The next section contains five excellent overviews of feedback between life and climate (S. E. Alexander, S. H. Schneider and K. Laggerquist); biodiversity and ecosystem function (D. Tilman); and the services provided by soils (G. C. Daily, P. A. Matson and P. M. Vitousek), pollinators (G. P. Nabhan and S. L. Buchmann) and natural enemies contributing to the control of agricultural pests (R. L. Naylor and P. R. Ehrlich).

All these chapters succeed in orienting general readers to the topic, yet also provide comprehensive up-to-date summaries of recent research and guides to the relevant literature. The authors use sometimes ingenious methods of estimating absolute and marginal values of particular ecosystem services at regional and global scales.

The third section reviews services supplied by important biomes: marine (C. $\mathrm{H}$. Peterson and J. Lubchenco); fresh water (S. Postel and S. Carpenter); forest (N. Myers); and grassland (O. E. Sala and J. M. Paruelo).

Postel and Carpenter point out that while fresh water has no substitute, its value under certain limiting conditions can be estimated from the replacement costs of using desalinized sea water. This practice is currently largely confined to the Persian Gulf where nations convert oil wealth to water at a cost of \$1-\$2 per cubic metre. In the less water-starved and less wealthy arid western United States, their analysis shows that today's marginal value of water for recreation, fisheries and other in-stream uses often exceeds the marginal value of water diverted for agriculture, so that "if the water market were freer, fewer diversions would be economically justified".

The next section contains miscellaneous case histories including a chapter on marine resource extraction (L. Kaufman and P. Dayton); a survey of the value of global biodiversity (N. Myers); tradeoffs between environmental conservation and development in a community in the Rocky Mountains in the United States (A. Wilcox and J. Harte); a discussion of the uses of natural and reconstructed wetlands (K. C. Ewel); and an analysis by R. M. Cowling, R. Costanza and S. I. Higgins of whether beating back the invasive exotic vegetation threatening the fynbos (a hard-leafed, fireprone shrubland) ecosystem of South Africa can be economically justified (it can).

A particularly fascinating chapter in this section by K. S. Bawa and M. Gadgil reviews ecosystem services used by people in subsistence economies, and discusses the feasibility of enlisting these people in efforts to preserve their local biodiversity. Follow- ing R. F. Dasmann, Bawa and Gadgil distinguish "ecosystem people" who rely on local ecosystems for most of their resources from "biosphere people", such as urbanites whose resources are drawn from much of the planet. Environmental degradation caused by resource extraction is generally invisible to biosphere people, but has immediate and sometimes tragic consequences for ecosystem people, such as the ecological refugees displaced by dams, deforestation or anthropogenic desertification.

Bawa and Gadgil point out that ecosystem people have conserved biodiversity and natural resources "when these serve the longterm interests of a small, well-knit human group". They offer practical ideas for fostering social and economic conditions that would permit these people to remain stewards and beneficiaries of their lands.

Yvonne Baskin's The Work of Nature is a well-written popular account of the recent investigations of community ecologists and ecosystem scientists whose findings are relevant to ecosystem services. With many vivid examples, Baskin reviews research that illustrates how species interactions influence ecosystems, emphasizing that some species that appear unnecessary or 'redundant' today may prove crucial tomorrow as conditions or circumstances change.

Her chapters reviewing keystone species and community interactions are gems, as is her lucid treatment of the adverse impact of invading species on the health of forests, fisheries or humans. Later she discusses ecosystem-level investigations of how soil and vegetation interact with climate and hydrology. She then reviews the fascinating studies of $\mathrm{N}$. Owen-Smith, P. Martin, and S. Zimov, T. and M. Chapin and their colleagues who, in Africa, North America and Beringia respectively, have built cases for continental scale impacts of prehistoric humans who eliminated megaherbivores.

In her chapter "Do we still need Nature?" Baskin discusses the failure of the $\$ 150$ million Biosphere II project, in which the atmosphere suffered from overproduction of carbon dioxide and underproduction of oxygen. She relates several other cautionary tales of failed engineering fixes that attempted to replace free natural services lost as ecosystems degraded.

With specific case studies such as the pollution of estuaries by cage culture of salmon, she illustrates problems that arise when local owners and beneficiaries are not paying for the loss of services from ecosystems that they overwhelm and degrade. As Daniel Schneider has pointed out in his work on the conversion of the Illinois River floodplain to cornfields, in contrast to Hardin's "tragedy of the commons" model, the most severe environmental degradation can follow the privatization of formerly public lands.

Both books are 'must reads' for teachers, students, scientists and citizens at all levels of expertise. The valuation of nature should be considered and widely debated by all concerned with humanity's future.

Pricing nature may disturb and depress 'green' readers. They should keep reading, for these authors are not among those "for whom every value can be made monetary", to use Naylor and Ehrlich's phrase. The authors do not believe that nature's only purpose is to comfort, support or amuse humans. They have simply confronted the reality that, in the world as it is today, putting a minimum monetary estimate on nature's services is the only way to slow, and hopefully eventually to stop, the loss of its crucial life-support functions.

Mary Power is in the Department of Integrative Biology, University of California at Berkeley, Berkeley, California 94720, USA.

\section{Science in the service of the Raj}

\section{The Science of Empire: Scientific Knowledge, Civilization, and Colonial Rule in India \\ by Zaheer Baber \\ State University of New York Press: 1996. \\ Pp. 298. \$71.50, $\mathfrak{E} 55.75$ (hbk); \$23.95, $\mathfrak{E} 18.75$ (pbk) \\ Mapping an Empire: The Geographical Construction of British India, 1765-1843} by Matthew H. Edney

University of Chicago Press: 1997. Pp. 436.

$\$ 35, \mathfrak{2} 27.95$

\section{Ehsan Masood}

Step onto any main thoroughfare in New Delhi, Mumbai (Bombay), Lahore or Karachi, and you'll find that the traffic drives on the left, just as it does in Britain. Step into an office, and you'll be offered tea with milk and sugar served by uniformed men still quaintly referred to as 'peons', the name given to the native servants of the Raj.

The imperial crown fell with the creation of India and Pakistan on 14 and 15 August 1947. But, by mostaccounts, the shadow of the Union Jack, the gaberdine suit and the khaki helmet still looms large.

English remains the language of business and education. Application forms are completed 'in triplicate. 'Oxford' is a name used by garment manufacturers and nursery schools. The school leaving examination is still called a 'matriculation'. A university student with high enough grades will graduate with 'honours'. And, should he want to become a scientist, he may end up working for the Council for Scientific and Industrial Research.

Two books on the role of science in the spread of empire published in time for the fiftieth anniversary of independence confirm 